\title{
Place of Surgery for Bilateral Bronchectasis in Kartagener Syndrome (About two Cases)
} \author{
Ouadnouni Yassine ${ }^{1,2}$ and Smahi Mohamed ${ }^{1,2}$ \\ ${ }^{1}$ Department of Thoracic Surgery, Morocco \\ ${ }^{2}$ Faculty of Medicine and Pharmacy, Morocco \\ *Corresponding author: Harmouchi Hicham, Department of Thoracic Surgery, Morocco
}

Lakranbi Marouane ${ }^{1,2}$, Harmouchi Hicham ${ }^{1 *}$, Sani Rabiou ${ }^{1}$, Ammor Fatimazahra ${ }^{1}$, Belliraj Layla ${ }^{1}$,

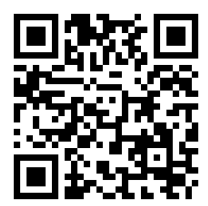

\section{ARTICLE INFO}

Received: 幽 July 22, 2019

Published: 幽 August 07, 2019

Citation: Lakranbi Marouane, Harmouchi Hicham, Sani Rabiou, Ammor Fatimazahra, Belliraj Layla, Ouadnouni Yassine, Smahi Mohamed. Place of Surgery for Bilateral Bronchectasis in Kartagener Syndrome (About two Cases). Biomed J Sci \& Tech Res 20(3)-2019. BJSTR. MS.ID.003442.

\begin{abstract}
Kartagener syndrome is a rare disorder characterized by association of chronic sinusitis, bronchiectasis, and situs inversus. Bronchiectasis lesions can be localized in unilateral or bilateral sides. This manuscript describes two cases presenting kartagener syndrome with bilateral bronchiectases comparing to the literature review. We concluded that lung resection for bronchectasis is strongly indicated in Kartagener syndrome, especially in the case of localized forms.
\end{abstract}

Keywords: Abomasum; Abomasum Nematodes; Ruminants

\section{Introduction}

Kartagener syndrome is an exceptional genetic disease with autosomal recessive inheritance. Its incidence is approximately 1 in 32.000 live births [1,2]. It is characterized by the triad: chronic bronchorrhea with bronchiectasis, chronic sinusitis and situs inversus. This syndrome is part of a nosological framework of ciliary immobility called the primary ciliary dyskinesia [3]. Bronchiectasis involvement, which can be localized in unilateral or bilateral sides, is then an indication for surgical resection [4]. We report the case of a bilateral surgical resections for bronchectasis on Kartagener syndrome and we will discuss the interest of surgery for bronchiectasis in this nosological setting.

\section{Observation 1}

This is Miss K.R aged 21 years old, having a history of chronic sinusitis with operated adenoids, having since childhood chronic bronchorrhea aggravated by intercurrent episodes of hemoptysis of low abundance significantly altering the quality of life. The clinical examination finds a peak shock in the right lateral-sternum with bilateral basithoracic rales. The chest x-ray showed basithoracic areolar images with right side angle images associated with signs of left pulmonary collapse (Figure 1). Thoracic abdominal CT objectified a situs inversus with bronchiectasis lesions of the left middle lobe and the right lingula (Figures 2 \& 3). Spirometry revealed a restrictive syndrome. After intensive respiratory physiotherapy, the patient underwent a middle left lobectomy with simple postoperative follow-up. The evolution was marked by a clear clinical improvement. Six months later, the patient benefited from the right side of a lingulectomy with anterior basal and lateral basal segmentectomy. The evolution was marked by a virtual disappearance of clinical symptomatology with reintegration of a normal quality of life, and the CV went from $60 \%$ in the sixth month after the second intervention to $71 \%$ one year later. 


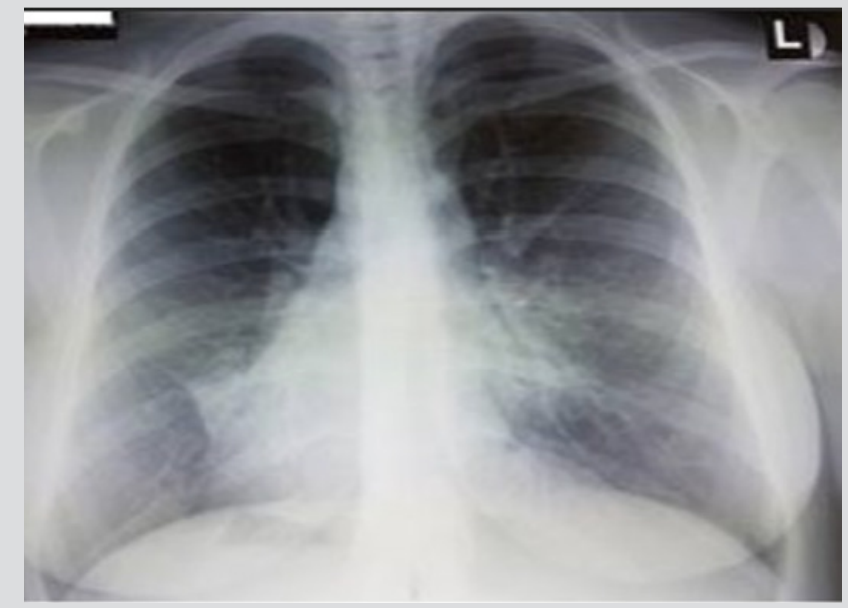

Figure 1: Chest $X$-ray showing areolar images in basithoracic region with right-angled image associated with signs of left pulmonary collapse.

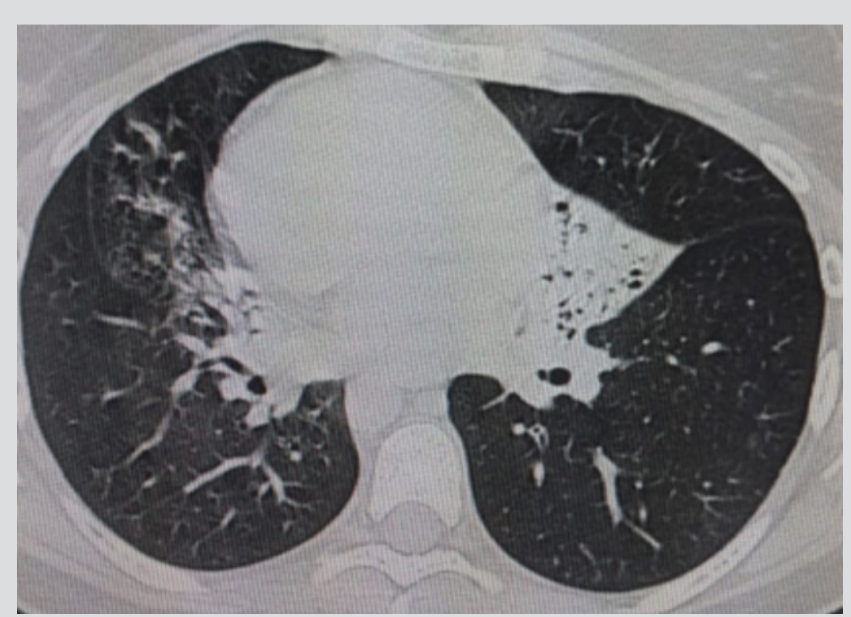

Figure 2: Parenchymal section of thoracic CT scan showing condensation left middle lobe and right Lingula with bronchiectasis.
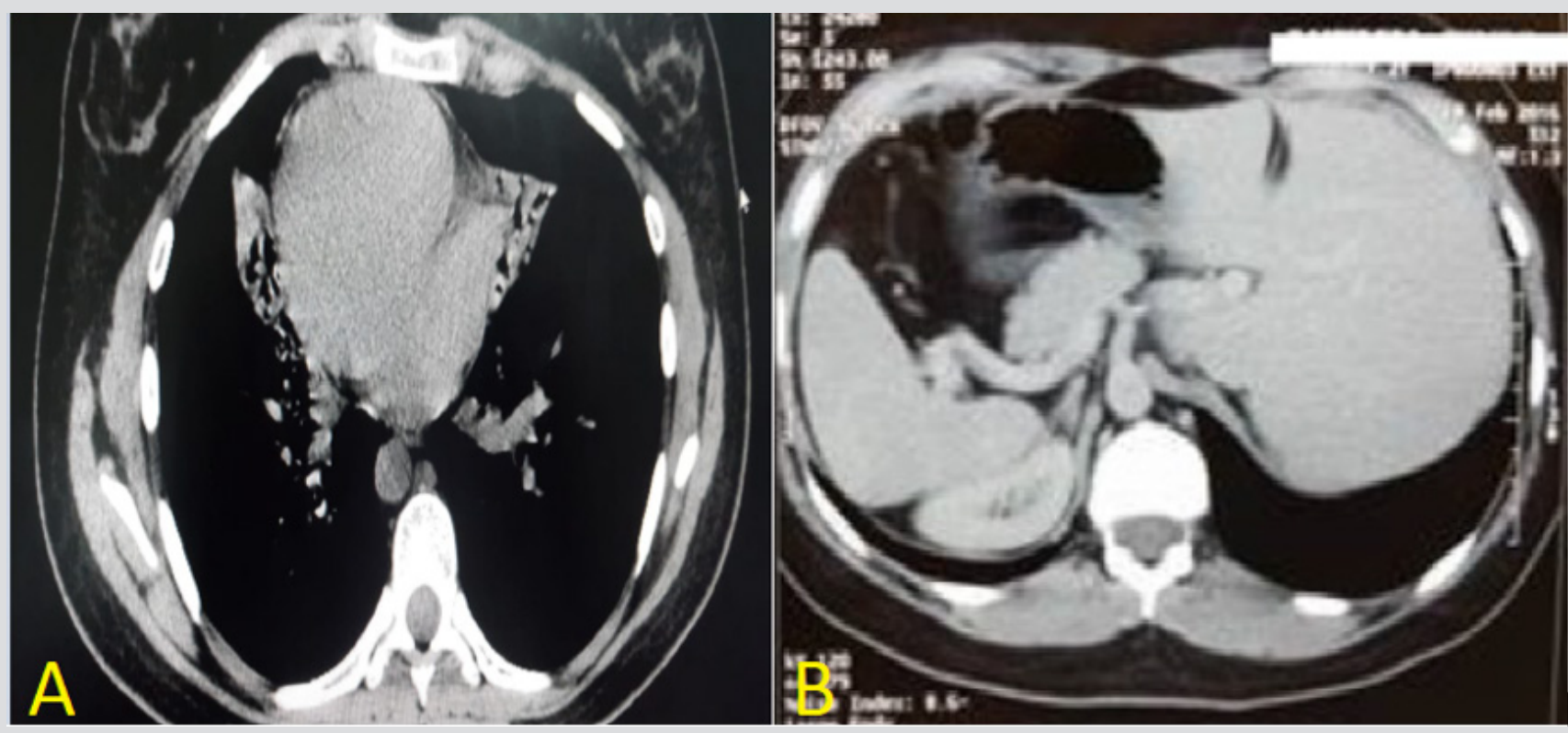

Figure 3: A) Mediastinal section showing dextrocardia. B) Abdominal section showing the seat of the liver in the left hypochondrium.

\section{Observation 2}

This is Miss K.E, 19 years old, treated for pulmonary tuberculosis in 2013 declared cured, followed for complete situs inversus, who has had dyspnea associated with bronchorhea without hemoptysis for 5 years. The whole evolves in a context of apyrexia and conservation of the general state. The general and thoracic clinical examination of the patient is without particularity. The patient received a chest X-ray showing a situs inversus with right basithoracic areolar images. The chest CT scan objectified a situs inversus with bilateral bronchiectasis foci in the middle lobe, right lower lobe and lower left lobe (Figures 4 \& 5). The respiratory function assessment of the patient showed a FEV1 of 2.8l. The patient initially underwent surgery on the left side with a middle lobectomy with left paracardial segmentectomy of the basal pyramid. The immediate postoperative follow-up was without particularity. Bronchorrhea was decreased by $50 \%$ after the first surgery, but always with a disturbance in the quality of life of the patient. The FEV1 after first surgery was 2.11. Six months after the first surgery, a decision to operate the patient on the right side was retained with FEV1 of 2.1l, and the patient underwent resection of the right basal pyramid and the lingula. The period of follow-up was one year with complete disappearance of bronchorrhaea. 


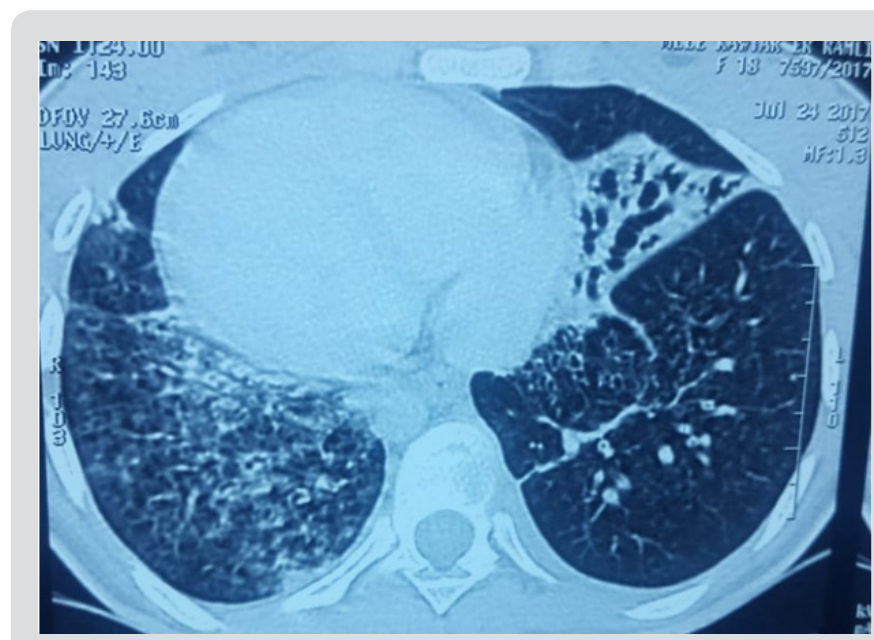

Figure 4: Thoracic parenchymal window CT showing bilateral bronchiectasis.

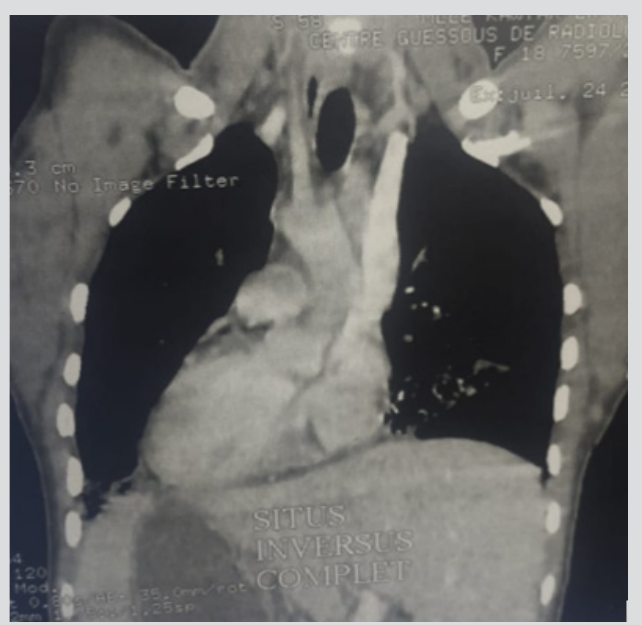

Figure 5: Chest CT scan in frontal section showing dextrocardia.

\section{Discussion}

The triad: situs inversus, bronchiectasis and sinusitis was first described by Siewert in 1904, then Kartagener in 1933 described this triad as a separate nosological entity [5]. The main physiopathological disorder consists of ciliary immobility affecting the respiratory ephitlium and sperm cells resulting infertility in male with the development of bronchiectasis [6], which is not present at birth, but develops gradually following the accumulation of mucus in relation to ciliary immobility and thus the respiratory symptomatology can be very noisy with abundant bronchorrhea and recurrent broncho-pulmonary infections altering the ciliary immobility. The quality of life of the patients and the high prevalence of Pseudomonas aeruginosa infections [7]. The topography of this bronchectasis most often interests the left middle lobe, the right lingula as well as the lower lobes; it can be localized in unilateral or bilateral sides. Most of the surgical cases reported in the literature involve unilateral resections of the type of left middle lobectomy or right lingulectomy $[4,8]$. Our cases are distinguished by the bi- lateral localized lesions and having benefited from anatomical lung resections on both sides. The surgery of this form of bronchiectasis remains recommended because of localized situation of these lesions, and in order to avoid the evolution towards the destruction of other territories that can be a source of the development of a chronic pulmonary heart $[9,10]$. Moreover, the reported surgical cases recorded an important clinical improvement [11]. In our cases, the postoperative evolution in the medium term after the first surgery is marked by a complete disappearance of the symptoms in the first patient and improved quality of life by $50 \%$ for the second patient.

Surgery on the contralateral side was performed in both patients 6 months after the first intervention. It was indicated for the first patient because of presence of contralateral bronchiectasis on the thoracic CT even a complete disappearance of bronchorhea. While for the second patient, surgery on the contralateral side was done to erase the persistence of bronchorhea secondary to the presence of bronchiectasis on the non-operated side. The diagnosis at an early stage of bronchiectasis in the framework of Kartegener syndrome is essential, since it allows to intervene on localized lesions, and even present sometimes only on one side, which makes it possible to carry out limited lung resections that don't sound on the respiratory function afterwards. For this reason, patients with kartagener syndrome should regularly benefit from thoracic CT.

\section{Conclusion}

Bronchectasias in Kartagener syndrome should be diagnosed early, at a stage where they still have a unilateral or bilateral localized topography where the surgery is the treatment of choice that can guarantee a return to a normal quality of life and avoid evolution towards dramatic complications.

\section{Author Contributions}

All the authors contributed substantially to the authorship of this manuscript. I.I , FZ.A, L.B, M.L , Y.O, and M.S. were directly involved in the patient's care.

\section{Ethics}

All procedures performed in studies involving human participants were in accordance with the ethical standards of the institutional and/or national research committee and with the 1964 Helsinki Declaration and its later amendments or comparable ethical standards.

\section{Informed Consent}

Written informed consent was obtained from the patients for publication of this manuscript and any accompanying images.

\section{References}

1. Gupta S, Handa KK, Kasliwal RR, Bajpai P (2012) A case of Kartagener's syndrome: Importance of early diagnosis and treatment. Indian J Hum Genet 18(2): 263-267.

2. Pınar Kendigelen, Ayșe Çiğdem Tütüncü, Şafak Emre Erbabacan, Güner Kaya, Fatiș Altındaș (2015) Anaesthetic Management of a Patient 
with Synchronous Kartagener Syndrome and Biliary Atresia. Turk J Anaesthesiol Reanim 43(3): 205-208.

3. Pandit S, Choudhury S, Das A, Basuthakur S, Das SK (2014) A rare case of Kartagener's syndrome. J Nat Sci Biol Med 5(1): 175-177.

4. Marcus P Kennedy, Peadar G Noone, Margaret W Leigh, Maimoona A Zariwala, Susan L Minnix, et al. (2007) High-Resolution CT of Patients with Primary Ciliary Dyskinesia. AJR 188(5).

5. Berdon WE, McManus C, Afzelius B (2004) More on Kartagener's syndrome and the contributions of Afzelius and AK Siewert. Pediatr Radiol 34(7): 585-586.

6. King SM (2000) The dynein microtubule motor. Biochim Biophys Acta 1496(1): 60-75.

7. AS Dabhi, SR Chaudhari, PB Thorat, HB Pandya, MC Shah, et al. (2005) Kartagener's Syndrome: A Triad of Bronchiectasis, Situs Inversus, and Chronic Sinusitis. JIACM 6(3): 241-243.

ISSN: 2574-1241

DOI: 10.26717/BJSTR.2019.20.003442

Harmouchi Hicham. Biomed J Sci \& Tech Res

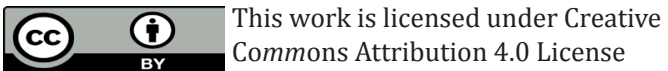

Submission Link: https://biomedres.us/submit-manuscript.php
8. Haiping Lin, Ziang Cao, Xiaojing Zhao, Qing Ye (2016) Left middle lobectomy for bronchiectasis in a patient with Kartagener syndrome: a case report. Journal of Cardiothoracic Surgery 11: 37.

9. Sha YW, Ding L, Li P (2014) Management of primary ciliary dyskinesia/ Kartagener's syndrome in infertile male patients and current progress in defining the underlying genetic mechanism. Asian J Androl 16(1): 101-106.

10. Sidney Filho LA, Machuca TN, Camargo JJ, Felicetti JC, Camargo SM, et al. (2012) Lung transplantation without the use of cardiopulmonary bypass in a patient with Kartagener syndrome. J Bras Pneumol 38(6): 806-809.

11. Haciibrahimoglu G, Fazlioglu M, Olcmen A, Gurses A, Bedirhan MA (2004) Surgical management of childhood bronchiectasis due to infectious disease. J Thorac Cardiovasc Surg 127(5): 1361-1365.

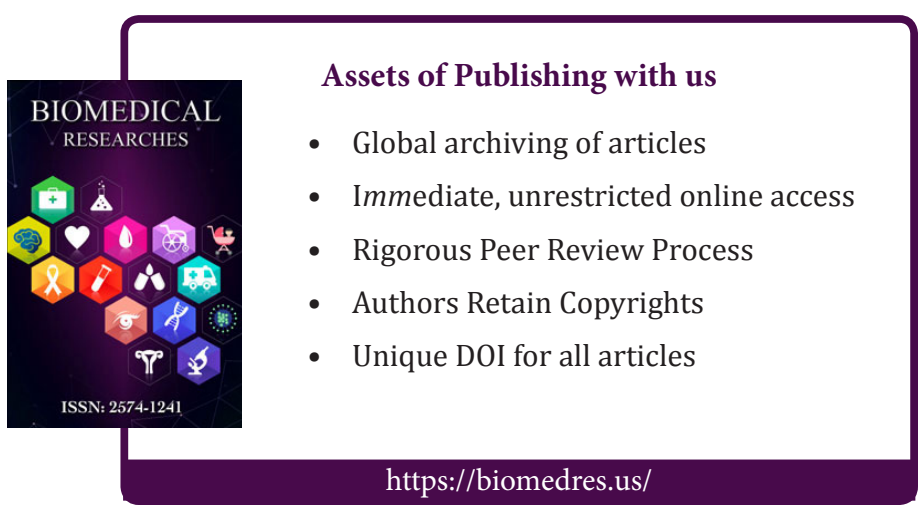

